\title{
0 Mito da Interdisciplinaridade: história e institucionalização de uma ideologia
}

\section{Luiz C. Martino e Katrine Tokarski Boaventura}

\section{Resumo}

0 trabalho apresenta questões que buscam melhor compreender a interdisciplinaridade do ponto de vista epistemológico. Levanta aspectos terminológicos (interdisciplinaridade, transdisciplinaridade, multidisciplinaridade, indisciplinaridade) e conceituais do termo a fim de discutir criticamente o projeto de convergência e unidade dos saberes. Discute a fragilidade epistemológica da proposta interdisciplinar e se pergunta pela difusão desse movimento, caracterizando-o como uma ideologia.

\section{Palavras-Chave}

Comunicação. Interdisciplinaridade. Epistemologia. Institucionalização da interdisciplinaridade. História da interdisciplinaridade.
Luiz C. Martino I martino@unb.br Professor do PPG em Comunicação da Universidade de Brasília-UnB. Pesquisador-CNPq.

Katrine Tokarski Boaventura I katrineboaventura@ gmail.com Doutoranda em Comunicação pela Universidade de Brasília - UnB. Bolsista da Capes.

\section{Introdução}

A interdisciplinaridade é um movimento que tem ganhado espaço no cenário intelectual a partir da década de 1960. 0 tema na verdade não é novo e a data tem por referência 0 interesse de entidades não-acadêmicas (como a UNESC0 e a OCDE) por questões relacionadas ao conhecimento científico. Ele está composto por uma série de posicionamentos, nem sempre conciliáveis, que cobrem diferentes dimensões, como: 0 ensino (composição de um currículo escolar), a aplicação prática (grupos de trabalho envolvendo diferentes especialistas em torno da solução de um problema prático comum) e a fundamentação do conhecimento científico (epistemologia).

Isto faz com que a discussão se desdobre em muitos assuntos e tenha características bastante diferentes em cada um desses âmbitos.

Nosso interesse se restringirá apenas à questão epistemológica, uma vez que os outros sentidos não são problemáticos, quer dizer, representam usos no qual a interdisciplinaridade não é oposta ao pensamento científico como "novo paradigma 
emergente". A questão surge, então, quando a interdisciplinaridade passa a ser vista como uma maneira alternativa de geração de conhecimento, que para alguns chega mesmo a ser considerada como uma superação da ciência.

Disciplinas menos consolidadas teoricamente, como a Comunicação e a Educação, ficam expostas a estas propostas radicais, de modo que alguns julgam encontrar na interdisciplinaridade uma maneira de resolver seus problemas de fundamentação, objeto e método. Contudo a própria falta de clareza sobre 0 sentido de interdisciplinaridade traz uma importante implicação epistemológica: dependendo da maneira como se compreenda a interdisciplinaridade, a consequência lógica é negar a possibilidade de que a Comunicação possa ser trabalhada como uma disciplina científica, além de criar embaraços para as atividades de ensino e pesquisa.

\section{Disciplina e Interdisciplinaridade}

Antes de tentarmos definir o que seria a interdisciplinaridade, faz-se necessário marcar que existe uma dificuldade que muitas vezes passa despercebida: entender o que é uma disciplina. A organização disciplinar se instituiu no século XIX:

Existe uma longa pré-história semântica da disciplina como um termo para organizar 0 conhecimento com propósitos de instrução em escolas e universidades. Mas somente 0 século XIX estabeleceu verdadeiros sistemas de comunicação disciplinares. Desde então a disciplina funciona como uma unidade da formação estrutural no sistema social da ciência, nos sistemas de educação superior, como um assunto do dom ensino e aprendizagem nas escolas, e finalmente como uma designação de papéis ocupacionais e profissionais (STICHWEH, 2001, p. 13727).

Outro aspecto relevante, segundo Stichweh, é a emergência das comunidades de especialistas. 0 surgimento das disciplinas equivaleria à emergência das comunidades científicas, teorizadas desde Thomas Kuhn:

As comunidades científicas repousam na intensificação da interação, conhecimento especializado compartilhado, certos valores em comum, e a orientação dos membros da comunicação em direção a uma constelação de problemas constitutivos da respectiva disciplina. A ciência moderna não se baseia nas realizações de indivíduos extraordinários, mas na força epistêmica das comunidades disciplinares (STICHWEH, 2001, p.13728).

A disciplina seria "uma comunidade de conversação com uma tradição de argumentação" (SHOTTER, 1997, apud CRAIG, 1999, p. 124).

Sua "particularidade nasce de um campo material específico, do assunto, do conjunto de problemas e de um repertório compartilhado de conceitos, métodos e ferramentas analíticas" (KLEIN, 1990, p. 267 apud SHOLLE, 1995, p. 129).

É importante refutar a ideia de que as disciplinas sejam meros instrumentos classificatórios. Ao contrário do que muitas vezes é colocado pelos defensores da interdisciplinaridade (e particularmente da transdisciplinaridade), que 
se alinham a uma compreensão naturalizada e corrente de que as disciplinas científicas seriam apenas um arranjo administrativo que reparte os saberes, não se pode perder de vista que “(...) uma disciplina não se resume a um simples problema de burocracia universitária. Em matéria de epistemologia, o termo disciplina corresponde a uma designação das peculiaridades de um tipo de abordagem, recorte e problematização do real (MARTINO, 2003, p. 86-87)".

Toda disciplina em ciências humanas e sociais gera um olhar sobre o mundo, e não apenas sobre um objeto; se cada uma acaba se concentrando em determinados pontos, é porque, de sua perspectiva, estes Ihes parecem ser os pontos mais relevantes para a compreensão do Homem, este objeto genérico comum a todas elas: trata-se de sua contribuição para compreensão do universo humano. 0 que chamamos de "disciplinas" nada mais é do que a designação de uma dessas perspectivas fundamentais através das quais se tenta apreender a significação do homem, objeto cuja totalidade, assim como qualquer outro, é inacessível através do discurso (nenhum discurso pode abarcar e esgotar a realidade). É um erro ingênuo, e nem por isso pouco disseminado, acreditar que a divisão disciplinar corresponde a uma repartição qualquer das "coisas" e do mundo. Desconsidera-se, assim, um importante papel da teoria, que não somente explica, mas constrói seu objeto (MARTINO, 2004, p. 8).

Um dos equívocos mais correntes daqueles que defendem a interdisciplinaridade é não procurar compreender a razão epistemológica para a existência de "disciplinas": que exigências levam o conhecimento científico a se repartir dessa forma? Sem essa análise a questão epistemológica é desarticulada, não tem sentido, parecendo apenas um problema de decisão

política ou administrativa.

Por fim, com relação à terminologia, vários termos são empregados: interdisciplinaridade, transdisciplinaridade, pluridisciplinaridade, multidisciplinaridade e outros. Morillo, Bordons e Gómez (2003) observam que não é um ponto pacífico para os diferentes autores, mas sustentam que interdisciplinaridade pode ser usado como um termo guarda-chuva, para designar diferentes práticas "trans-disciplinares" (cross-disciplinary). Segundo as autoras:

As definições mais comumente aceitas vêm da OCDE [Organização para a Cooperação e Desenvolvimento Econômico] (1998), na qual multidisciplinaridade, interdisciplinaridade, e transdisciplinaridade são usadas para se referir a um nível crescente de interação entre disciplinas. Assim, na pesquisa multidisciplinar 0 assunto estudado é abordado de diferentes ângulos, usando diferentes perspectivas disciplinares, e não é realizada a integração entre elas. A pesquisa interdisciplinar leva à criação de uma identidade teórica, conceitual e metodológica, assim resultados mais coerentes e integrados são obtidos. Finalmente, a transdisciplinaridade vai um passo além e se refere a um processo no qual a convergência entre as disciplinas é observada, e acompanhada por uma integração mútua das epistemologias disciplinares (Van den Besselaar \& Heimeriks, 2001) (MORILLO, BORDONS, GÓMEZ, 2003, p. 1.237).

Japiassú e Marcondes adotam uma definição de interdisciplinaridade, em seu "Dicionário Básico de Filosofia", que apresenta pontos de convergência com as anteriores: 
Interdisciplinaridade - correspondendo a uma nova etapa do desenvolvimento do conhecimento científico e de sua divisão epistemológica, e exigindo que as disciplinas científicas, em seu processo constante e desejável de inter-penetração, fecundem-se cada vez mais reciprocamente, a interidisciplinaridade é um método de pesquisa e de ensino suscetível de fazer com que duas ou mais disciplinas interajam entre si. Esta interação pode ir da simples comunicação das ideias até a integração mútua dos conceitos, da epistemologia, da terminologia, da metodologia, dos procedimentos, dos dados e da organização da pesquisa. Ela torna possível a complementaridade dos métodos, dos conceitos, das estruturas e dos axiomas sobre os quais se fundam as diversas práticas científicas. 0 objetivo utópico do método interdisciplinar, diante do desenvolvimento da especialização sem limite das ciências, é a unidade do saber. Unidade problemática, sem dúvida, mas que parece consituir a meta ideal de todo saber que pretende corresponder às exigências fundamentais do progresso humano (JAPIASSÚ \& MARCONDES, 2001, p. 145-146).

De fato existem muitas definições e termos, ao longo desse artigo iremos nos servir do sentido amplo (guarda-chuva), empregando, portanto, o termo interdisciplinaridade em sua acepção genérica. Contudo, o que as definições acima não explicam é porque devemos esperar que da confrontação de conhecimentos de diferentes disciplinas deva necessariamente haver convergência e "integração mútua". Claro, isto pode ou não ocorrer - inclusive com conhecimentos oriundos de uma mesma disciplina. Em ciência, a unidade do saber não é uma síntese, um consenso. A contradição de teses, a concorrência teórica, a heterogeneidade dos conhecimentos, não é algo a se lamentar ou a ser superado, é a realidade e o motor do conhecimento científico. Uma crítica séria às disciplinas científicas deveria levar isso em consideração. A especialização não deve ser vista como um mal em si, antes de mais nada ela reflete a diversidade necessária à ciência.

\section{0 Código Da Vinci da interdisciplinaridade: origens e institucionalização}

Embora a interdisciplinaridade esteja visceralmente ligada a uma oposição ao conhecimento científico moderno, muitas das questões levantadas não são propriamente novas.

0 tema da interdisciplinaridade sempre retorna. Estabelecido no imaginário da completude que superaria as divisões próprias de cada disciplina, ou na feliz mescla que reúne tudo em um pastiche que dissolve as peculiaridades isoladas, volta com a insistência dos arquétipos inconscientes, e se estabelece de novo em cada ocasião como se fosse a primeira [vez] (FOLLARI, 2005, p. 7).

Desde a Antiguidade os filósofos já se inquietavam sobre a natureza do conhecimento. Aristóteles, por exemplo, distinguia duas formas: o nous (noesis, noos, intelecto, cognição, pensamento) e a dianóia (através do pensamento). 0 primeiro termo se refere a um conhecimento imediato, instantâneo e global, traduzido para o latim como intuição. 0 segundo termo designa 0 conhecimento como processo, o pensamento discursivo, que discorre e se desdobra, atravessando várias etapas, níveis, perspectivas. 
A questão da interdisciplinaridade pode ser delimitada e precisada a partir desses dois modos do pensamento, pois se ela aspira à totalidade do primeiro, de outra parte os adeptos da interdisciplinaridade acreditam encontrar nas diferentes disciplinas (ou em sua superação) os meios teóricos e epistemológicos para efetivar esta unidade do conhecimento. Ao contrário da concepção aristotélica, a unidade interdisciplinar não é dada de imediato (intuição), mas deve ser construída (cooperação, cruzamento). Os teóricos da interdisciplinaridade aspiram estabelecer a unidade do conhecimento através do processo e como um processo, sem renunciar à discursividade. Contudo parece não estarem muito atentos à profunda relação entre pensamento e linguagem, à função enformadora do discurso em relação à realidade (conceito), onde se fundamenta a necessidade e a diversidade teórica.

Outros aspectos da filosofia antiga também podem ser levantados. No eclipsar da filosofia grega surgem dois movimentos interdisciplinares: sincretismo e ecletismo. Ambos se caracterizam por uma rejeição à posição dogmática, na busca de possibilidades consensuais e conciliatórias: a verdade seria construída a partir de elementos tomados emprestados de várias correntes de pensamento. $\mathrm{E}$ ambos representam posicionamentos em relação à diversidade dos saberes, sendo que o ecletismo, no entanto, se diferencia do sincretismo, pois pretende possuir critério de seleção, um princípio a partir do qual teorias aparentemente diversas possam ser harmonizadas, enquanto que 0 sincretismo é entendido como mera fusão de elementos discordantes (FERRATER MORA, 1999, p. 3293).

Tais posicionamentos coincidem com as divergências do movimento interdisciplinar. Primeiramente, na premissa comum de que as diferentes doutrinas/disciplinas encerram verdades parciais, as quais devem ser recolhidas e tratadas (depuradas, corrigidas, potencializadas) a partir de sua integração a totalidades maiores, única forma de aceder à verdade. Depois, quanto ao problema da diversidade de conhecimentos e ao choque de disciplinas, questiona-se se daí resultaria: 1) uma fusão e, portanto, uma nova disciplina (gênese de novas disciplinas); ou 2) se este choque seria o modo de viabilizar a formação de um saber superior, a partir de elementos selecionados de outras doutrinas, os quais encerram verdades incompletas (interdisciplinaridade $=$ composição de saberes para formar um saber superior); ou ainda, 3) a superação de todas as fronteiras do saber, caracterizando um saber de ordem superior.

Abandonando a filosofia grega, não podemos deixar de citar, no período medieval, a emergência da universidade. Embora esta tenha trazido uma organização do ensino - o trivium (lógica, gramática, retórica) e o quadrivium (aritmética, geometria, astronomia e música) - a origem da repartição disciplinar dos saberes, na verdade, só aparecerá mais tarde, pois estas divisões se mostravam muito abertas, longe do sentido 
moderno do termo (a gramática, por exemplo, era a arte de interpretar, não somente 0 texto, mas qualquer realidade). Da mesma forma, a erudição humanista dos sábios da Renascença ou naturalista do período clássico não conhecia as disciplinas como "fronteiras" ou limites de domínios especializados. A diversidade dos saberes encontra sua unidade no sábio, no erudito, enfim, naquele que encerra os conhecimentos e os organiza enquanto uma organicidade do tipo filosófica. Até mesmo a universidade moderna, em seus primórdios (século XIX e início do século XX), ainda está bastante influenciada pela erudição clássica, que atravessa os vários saberes, sem marcar a especialização.

Esta breve trajetória histórica pode ser resumida na constatação de que a repartição em disciplinas e a especialização do conhecimento são características do conhecimento científico, o que fica mais nítido com o desenvolvimento deste. A ciência difere, portanto, da filosofia, que é intrinsecamente um saber inter/trans disciplinar. Daí o mal-estar da crítica interdisciplinar mais radical, pois 0 ataque e a desclassificação do pensamento científico podem soar como uma volta a um estado pré-científico (erudição naturalista, sabedoria de vida, ética humanista...) ou como um descabido exercício de apregoar a superioridade da especulação filosófica sobre o trabalho científico, quando na verdade são conhecimentos de ordens diferentes.

Por conseguinte, stricto-sensu, as origens recentes da interdisciplinaridade devem ser buscadas mais avante e estão ligadas à consolidação das ciências. Particularmente nas ciências humanas ou sociais, que constituem nosso foco, o processo de institucionalização do pensamento interdisciplinar cumpre um papel de primeira importância, até aqui subestimado ou pouco explorado.

A interdisciplinaridade tem sido apresentada como um pensamento espontâneo, uma "revolta popular" legitimamente dirigida pelos princípios de emancipação e aspirações libertárias contra uma suposta estreiteza do espírito científico e suas amarras disciplinares. Não raro, ela aparece como uma descoberta pessoal, fruto de uma inquietação intelectual, nascida do inconformismo de um sujeito que busca se libertar dos horizontes da ciência, considerados restritos e opressores. Na verdade, como qualquer outro movimento intelectual, a interdisciplinaridade tem sua história, suas instituições e sua ideologia. Mas o fato desta história não ser contada, a pouca atenção dada a seus componentes institucionais, seus veículos de difusão e sustentação, reforça o matiz ideológico do movimento e 0 torna invisível à critica.

É sabido que uma das vertentes ideológicas que inspiraram a interdisciplinaridade é o Maio de 68 , movimento estudantil complexo. Uma das correntes aí presentes, a New Left, reduzia as universidades a simples aparelhos ideológicos, meros instrumentos da luta política. 
De modo que outra vez está em cena a reinventada proposta do interdisciplinar, reprimida sua origem para que não seja advertida no que tem de repetição e de retorno. Com roupagens às vezes mudadas, às vezes idênticas, isto já se viveu nos anos setenta, como uma resposta às propostas dos alunos rebeldes de maio de 68 (Follari, 1982 e 1990). A interdisciplinaridade encheu rios de tinta, legitimou programas em eleição para autoridades universitárias, agraciou informes de atividades, sem nunca ter encontrado os princípios epistemológicos que a tiraram do plano de proposta política até 0 da viabilidade acadêmica e da fecundidade investigativa. De tal modo, se perdeu no esquecimento nos anos oitenta, até que no fim dos anos noventa, vivemos um revival que, para ser plenamente - decidiu prescindir das citações e de outras elegâncias que fazem 0 repertório, por exemplo, dos remakes cinematográficos. Neste caso, ninguém parece saber que o tema teve um auge anterior, ou ninguém quer se dar conta de que 0 sabe. De modo que no campo discursivo, estamos (re)descobrindo continentes já descobertos (FOLLARI, 2005, p. 7-8).

\section{A institucionalização da interdisciplinaridade} acontece no período de pós-guerra. Ela é fomentada por instituições como a UNESCO (Organização das Nações Unidas para a Educação, a Ciência e a Cultura), fundada em 1945, e a OCDE (Organização para a Cooperação e Desenvolvimento Econômico), fundada em 1961 e sucessora da Organização para a Cooperação Econômica (OECE, de 1948). Fundações como a Calouste Gulbelkian também contribuíram. Essas instituições são responsáveis pela organização dos principais congressos e publicações sobre o assunto; e pelas fontes mais consultadas e citadas na bibliografia especializada.
Vejamos algumas passagens dessa história institucional. Em 1968 a Unesco, através de sua Revue Internationale des Sciences Sociale publica um número inteiro dedicado ao assunto, intitulado "Pesquisa focada em problema multidisciplinar". Logo em seguida, a OCDE organiza o Colóquio Internacional sobre Interdisciplinaridade, realizado em Nice em 1970, que talvez seja o primeiro evento de grande envergadura.

Em 1977, a Unesco reforça a bibliografia de referência, através dessa mesma revista ela publica o número "Facetas da interdisciplinaridade" e em 1983 o livro Interdisciplinaridade e Ciências Humanas. Ela também organiza 0 Colóquio Internacional sobre Interdisciplinaridade, em Paris, em 1991. A publicação das comunicações ficou a cargo de um especialista em literatura, Eduardo Portella (ex-ministro da Educação do governo João Figueiredo): Entre savoirs. Linterdisciplinarité en actes: enjeux, obstacles, perspectives. (Toulouse, 1992). № ano de 1994 a Unesco iria apoiar o I Congresso Mundial da Transdisciplinaridade (Convento da Arrábida, Portugal) organizado pelo CiretCentro Internacional de Pesquisas e Estudos Transdisciplinares (fundado em 1987). É desse encontro que sai, sob a forma de um manifesto, a Carta da Transdisciplinaridade, cuja redação foi elaborada por Lima de Freitas, Edgar Morin et Basarab Nicolescu. 
Em 1999 a OCDE organizou o seminário "As

Ciências Sociais em um Ponto de Virada?" ("The

Social Sciences at a turning point?"). E no

mesmo ano se engaja no projeto "Re-inventar

as Ciências Sociais", que comporta um ciclo de

quatro "workshops" (formação prática): Ottawa

1999 (The Social Sciences for a Digital World:

Building Infrastructure for the Future);

Bruges 2000 (The contribution of the Social

Sciences to Knowledge and Decision Making),

Tóquio 2000 (Social Sciences and Innovation), culminando com o evento de Lisboa em 2001, de onde sai "A Declaração sobre o Fortalecimento do Papel das Ciências Sociais na Sociedade"

(Declaration on Strengthening the Role of the

Social Sciences in Society).

0 teor desses empreendimentos pode ser

observado na publicação "Re-inventar as Ciências

Sociais", documento chamado de "relatório", que resume e dá voz ao ciclo de "workshops" da OCDE.

Ele dispõe o problema em três eixos de reflexão:

1) Ciências sociais e mudança social; 2) Alteração

do papel das ciências sociais; 3) 0 que as políticas públicas podem fazer?

Vê-se que as ciências sociais aparecem totalmente voltadas para a intervenção social, inclusive, como sugerido no segundo item, elas devem ser "alteradas" para cumprir esta função.

No artigo "From Opening to Rethinking the Social Sciences", Luk Van Langenhove apresenta este ponto de vista:

\begin{abstract}
Minha posição pessoal é que é realmente necessária uma reformulação radical das ciências sociais. As organizações internacionais podem desempenhar um interessante papel em tal processo, tornando os governos cientes dos problemas em seus sistemas nacionais de ciências sociais e estimulando o desenvolvimento de novas abordagens. A organização institucional das ciências sociais será um grande obstáculo na mudança das ciências sociais. Os governos podem intervir no uso do dinheiro público disponível para estimular novas iniciativas transdisciplinares (2004, p. 64 , grifos nossos).
\end{abstract}

Langenhove expõe claramente os objetivos imediatos e as estratégias de como alcançálos: as organizações não-acadêmicas devem pressionar os governos a gerarem políticas que disseminem a transdisciplinaridade, inclusive com uso de recursos financeiros (verbas de pesquisa, editais, bolsas de estudo, incentivos, premiações...).

Não estamos mais no universo acadêmico ou no ambiente das discussões científicas, onde idéias são debatidas e se impõem pelo convencimento de sua argumentação. 0 que temos aqui é 0 ethos da política, com as estratégias de agentes interessados em impor sua visão, disseminar sua ideologia, garantir os meios de reprodução de uma forma de pensar. Propor uma reformulação radical das ciências sociais é postular que haja algo completamente errado com elas. ou melhor, "diagnosticar" que haja algo de completamente errado abre espaço para as soluções de reformulação. Ora, em que se apóia tal diagnóstico? 
Aqui, eu gostaria de ampliar essa perspectiva com algumas ideas sobre as bases ontológicas e epistemológicas das ciências sociais. Ao meu ver, é o positivismo que impede as ciências sociais de terem mais poder generativo (cf. Van Langenhove, 1995). Por isso, a busca por uma abordagem não-positivista das ciências sociais que mantenha os mais altos padrões de solidez metodológica e controle de qualidade.

Estas colocações "ontológicas e epistemológicas" são totalmente inaceitáveis para aqueles que têm alguma familiaridade com a prática das ciências sociais ou com os debates epistemológicos. Um diagnóstico que comece por identificar toda a diversidade teórico-epistemológica dessas ciências com o positivismo só pode ser rejeitado, sem muito crédito. Afirmar que "é o positivismo que impede as ciências sociais de terem mais poder gerativo" é de um reducionismo atroz, bastante longe da realidade do campo teórico. Reaviva o mito do pan-positivismo, que seria um pensamento total e onipresente, poderoso e perigoso, mas que só existe na ficção-científica.

Nem precisamos insistir na análise detalhada da notável fragilidade da posição epistemológica de Langenhove - que, aliás, perpassa todos os grandes personagens desse movimento (Morin, Wallerstein, Nicolescu, etc.) -, mas devemos tentar entender como um projeto tão inconsistente ganhou credibilidade. Como algo tão pouco fundamentado do ponto de vista epistemológico, tão incoerente do ponto de vista político, pôde ganhar repercussão e difundir-se rapidamente? Que condições lhe permitiram se impor como uma alternativa válida? Por que teve acolhimento em setores do mundo acadêmico? Enfim, como um projeto tão ambicioso, que visa a radical transformação das ciências sociais pode ter credibilidade partindo de mitos como a "crise" da ciência ou de sua identificação com o pensamento dogmático e com 0 capitalismo, ou ainda, que as ciências sociais devam ser sumariamente reduzidas a uma posição positivista?

Se, de um lado, as respostas a estas questões não podem ser encontradas no âmbito epistemológico, de outro lado, elas revelam claramente seu lado ideológico. Mais que uma nova fundamentação para as ciências sociais, o que está em jogo são questões ideológicas. Por isso os preceitos podem ser vagos e inconsistentes. Embora sejam formulados por filósofos e cientistas, estes são recrutados por organizações não-acadêmicas para falar em nome da ciência e submetê-la a seus objetivos.

Lembremos que a OCDE, herdeira da OCEE (Organização para a Cooperação Económica Européia, 1948), nasce com o investimento estadunidense e o plano Marshall para reconstrução da Europa do pós-guerra. Assim como a Unesco, trata-se de uma instituição voltada para o desenvolvimento, trazendo as marcas dessa ideologia, que independentemente de seu valor (não é nosso propósito tecer julgamentos aqui), vê na ciência uma instrumento para implementar seus objetivos. 
Nem precisamos entrar em uma crítica ao desenvolvimentismo, o ponto focal é que estas instituições internacionais se vêem no direito de dizerem o que é o campo científico, de apontar os principais problemas de fundamentação epistemológica e no dever de intervirem junto aos governos nacionais para implementarem suas soluções para as ciências sociais.

Hoje esta ideologia invade as universidades e desloca a cultura acadêmica. Ela implementa planos e certezas que nada têm a ver com a forma de gerar conhecimento próprio à ciência, mas quer se impor como uma nova ou outra "epistemologia". 0 que é bastante conveniente para empresas comerciais, como coloca Follari em sua crítica a Gibbons (La nueva producción del conocimiento, 1997):

Aqui a questão é postulada em termos de superação do passado acadêmico, caracterizado pela existência das disciplinas com um sentido intra-teórico desengajado com as exigências que se atribui à "realidade". Esta última invoca com força as urgências do desenvolvimento econômico, que 0 autor [Gibbson] interpreta como as dos donos das grandes empresas. De tal modo, se trata de transladar o lugar de investigação passando da universidade para a empresa, do acadêmico para o produtivo-econômico, e de substituir o interesse pela explicação pelo interesse da aplicação (FOLLARI, 2005, p. 13).

Além de investimentos financeiros e estratégias políticas, esta ideologia reclama 0 reconhecimento de um status de conhecimento. Uma nova forma, mais "moderna", ou pós- moderna, que assume ares de cruzada moral

(vide Carta da Transdisciplinaridade).

No Brasil, segundo Ivani Fazenda, são os pedagogos os primeiros a se interessarem pelo tema.

$$
\begin{aligned}
& \text { No Brasil, a interdisciplinaridade chegou no } \\
& \text { final dos anos } 1960 \text { e, de acordo com Fazenda, } \\
& \text { com sérias distorções, como um modismo, } \\
& \text { uma palavra de ordem a ser explorada, usada } \\
& \text { e consumida por aqueles que se lançam ao } \\
& \text { novo sem avaliar a aventura. Diz ainda que, } \\
& \text { no início da década de 1970, a preocupa- } \\
& \text { ção fundamental era a de uma explicitação } \\
& \text { terminológica. A necessidade de conceituar, } \\
& \text { de explicitar, fazia-se presente por vários } \\
& \text { motivos: interdisciplinaridade era uma palavra } \\
& \text { difícil de ser pronunciada e, mais ainda, de } \\
& \text { ser decifrada. Certamente que antes de ser } \\
& \text { decifrada, precisava ser traduzida, e se não se } \\
& \text { chegava a um acordo sobre a forma correta de } \\
& \text { escrita, menor acordo havia sobre o significado } \\
& \text { e a repercussão dessa palavra que ao surgir } \\
& \text { anunciava a necessidade da construção de um } \\
& \text { novo paradigma de ciência, de conhecimento, e } \\
& \text { a elaboração de um novo projeto de educação, } \\
& \text { de escola e de vida (FAZENDA, 1999, p. } 16 \text {, } \\
& \text { apud TRINDADE, 2008, p. } 78 \text { ). }
\end{aligned}
$$

Na década de 1980, a interdisciplinaridade

continuou a se disseminar. 0 período foi caracterizado pela busca de princípios teóricos para as práticas vivenciadas por alguns professores. Já nos anos 1990, vários projetos surgiram com a denominação de interdisciplinares, baseando-se no "modismo e sem fundamentação", conforme Trindade (2008, p.79).

$\mathrm{Na}$ Comunicação, foi entre 0 final dos anos $60 \mathrm{e}$ o início dos anos 70 que principiou uma reflexão 
efetivamente latino-americana a respeito da comunicação, marcada pela influência da esquerda, que conquistava espaço no continente, e pela oposição ao american way of life e à indústria cultural que desembarcavam por aqui, num claro projeto de dominação política e cultural. Entretanto, essa onda de busca pela liberdade foi freada pelas ditaduras militares que se implantaram em vários países da América Latina, de modo que a teoria da comunicação esteve muito presa a este contexto histórico de resistência. A pesquisa acadêmica confundia-se com o comprometimento político e a prática de denúncia.

(...) Era preciso denunciar o funcionalismo, a televisão comercial, os fluxos internacionais da notícia, as histórias em quadrinhos, as políticas de comunicação (ou a falta delas), as corporações multinacionais, a Indústria Cultural, a estrutura transnacional de informação, 0 cinema de Hollywood, a manipulação ideológica, a publicidade e as pesquisas de opinião, as novas tecnologias, a miséria da informação, 0 imperialismo cultural (BERGER, 2001, p. 257).

A pesquisa em Comunicação no Brasil

coincide com o surgimento dos primeiros programas de pós-graduação, na década de 70 .

Sua institucionalização é marcada por uma contradição: ao mesmo tempo em que cresceram os cursos de pós-graduação em Comunicação no país ${ }^{1}$, avançou também 0 entendimento de que a área seria inter/transdisciplinar e que, portanto, não poderia configurar uma disciplina.
É no entroncamento dos processos de institucionalização acelerada dos estudos de comunicação com o crescimento da insatisfação generalizada com a sua disciplinarização no contexto das ciências sociais (Wallerstein) e, também, com a sociedade da comunicação, (Vattimo) que se pode identificar a institucionalização transdisciplinar dos estudos de comunicação a que remete o sociólogo italiano Mario Morcellini. Para a comunicação, vale a sua metáfora de que a comunicação é "indisciplinada" (Morcellini e Fatelli, 1996), o que a torna um "paradoxo" em face à aceleração do seu processo de institucionalização acadêmica, pelo menos desde a última década (LOPES, 2006, p. 24).

Na década de 80, a análise ideológica e a teoria da dependência econômica perderam força para a pesquisa-ação, caracterizada por uma perspectiva comprometida e militante do trabalho acadêmico, levando em conta a comunicação popular e alternativa, e tomando Gramsci como referência (BERGER, 2001). Este contexto de questionamento à ciência e de confusão das instâncias científica e política nas pesquisas desenvolvidas favoreceu o surgimento da discussão sobre interdisciplinaridade.

Na Capes, desde 1999, há uma área dedicada a este tipo de pesquisa. Em 2008, a Área Multidisciplinar passou a ser designada como Área Interdisciplinar, dentro da Grande Área Multidisciplinar. E seu desenvolvimento foi expressivo: desde que foi criada, apresenta a maior taxa de crescimento da Capes. Em 1999, eram 46 cursos cadastrados; e em 2008, 
o número já era de 258 (CAPES, 2009). Na

prática a institucionalização da abordagem

interdisciplinar parece ter resolvido algumas

pressões da demanda universitária.

Em primeiro lugar, a existência da Área propiciou e induziu na Pós-Graduação brasileira a proposição de cursos em áreas inovadoras e interdisciplinares, acompanhando a tendência mundial de aumento de grupos de pesquisa e programas acadêmicos tratando de questões intrinsecamente interdisciplinares e complexas. Em segundo lugar, a comissão serviu de abrigo para propostas de novos cursos de universidades mais jovens ou distantes, com estruturas de Pós-Graduação em fase de formação e consolidação, com dificuldades naturais de constituir densidade docente. Esta atuação deve ser entendida como importante para 0 sistema de Pós-Graduação nacional, na medida em que serve como elo de entrada de número expressivo de universidades em atividades de pesquisa e ensino de mais alto nível, contribuindo para aprimoramento de seu corpo docente e oferecendo oportunidades de formação avançada nas várias regiões do território nacional (CAPES, Documento de Área Interdisciplinar 2009, p. 1).

Vemos que foi uma preocupação desenvolvimentista que guiou a Capes a implementar cursos interdisciplinares. Curiosamente a interdisciplinaridade se torna uma área, uma "disciplina" no sentido burocrático, mas resta ainda saber se os trabalhos aí realizados podem ser realmente classificados como um novo tipo de conhecimento, fundado em nova epistemologia, ou apenas se enquadram nas possibilidades abertas pelos saberes das ciências.
A própria dificuldade de avaliar estes trabalhos

- não por seus resultados práticos, mas sua natureza epistemológica -, expõe um dos limites da produção interdisciplinar, que é 0 acompanhamento e a crítica ao trabalho de pesquisa, como uma necessidade para seu desenvolvimento. Ao contrário de um mito muito difundido, o trabalho interdisciplinar cria isolamento, pois os participantes não compartem nem a experiência da formação, nem de bibliografias comuns. Ele exige um esforço muito maior que o trabalho especializado (já bastante difícil) e corre o risco de apropriações e usos indevidos de conceitos de diferentes ciências, assimilando a produção de conhecimento ao trabalho de lidar com informação (como fica a questão da competência neste trânsito pelos diversos conhecimentos? Estaríamos autorizados a falar de física porque lemos alguns livros sobre 0 assunto? Até que ponto podemos discutir economia porque lemos algumas matérias nos jornais?). Também não podemos desprezar o risco de gerar idioletos ou de não se poder superar um nível muito superficial de contato entre pesquisadores, incapazes de acompanhar criticamente 0 trabalho de pesquisa ou de avaliar seus resultados.

Enfim, a discussão que hoje temos sobre a interdisciplinaridade não repousa em uma base epistemológica e tem pouco a ver com as questões do pensamento cientifico. São questões ideológicas, como mostra sua origem e desenvolvimento, 0 que de certa forma explica as fragilidades de suas bases. 


\section{Referências bibliográficas}

BERGER, Christa. A Pesquisa em Comunicação na América Latina. In: HOHLFELDT, A., MARTINO, L. C., FRANÇA, V. Teorias da Comunicação: conceitos, escolas e tendências. Petrópolis, RJ: Vozes, 2001. p. 241-277.

CAPES. Documento de Área - Área Interdisciplinar. Brasilia: Capes, 2009. Disponível em: http://capes. gov.br/component/content/article/44-avaliacao/4674interdisciplinar. Acesso em: 22 jun. 2012.

CRAIG, Robert T. Discursive Origins of a

Communication Discipline. In: National Communication Association. Miami Beach, FL, 21 nov. 2003. Disponível em: http://spot.colorado.edu/ craigr/ NCA03\%20Discursive\%200rigins.doc. Acesso em: 15 abr. 2012.

FAZENDA, Ivani. (org.). 0 que é

interdisciplinaridade? São Paulo: Cortez, 2008.

FERRATER MORA, José. Diccionario de Filosofia. 5

v. Nueva edición revisada, aumentada y atualizada por el profesor Josep-Maria Terricabras. Editorial Ariel. Barcelona, 1999.

FOLLARI, Roberto. La Interdisciplina Revisitada.

Andamios. Revista de Investigación Social, junio, 2005/vol. 1, número 002. Universidad Autónoma de la Ciudad de México, Distrito Federal, México, pp. 7-17. Disponível em: http://redaclyc.uaemex.mx. Acesso em: $12 \operatorname{dez} 2012$.

GUSDORF, G. Passe, présent, avenir de la recherche interdisciplinaire. Revue Internationale des Sciences Sociales, Paris, v. 29, n.4, 1977.

GUSD0RF, G. Passé, présent, avenir de la recherche interdisciplinaire, in : Facettes de l'interdisciplinarité, numéro de la Revue Internationale des Sciences Sociale, revue trimestrielle publiée par Unesco, Paris, Vol. XXIX, n.4, 1977.
JAPIASSÚ, Hilton; MARCONDES, D. Dicionário Básico de

Filosofia. 3 ed. Rio de Janeiro: Jorge Zahar Editor, 2001.

LANGENHOVE, Luk V. From Opening to Rethinking the Social Sciences

LOPES, Maria Immacolata V. Lopes. 0 Campo da Comunicação: sua constituição, desafios e dilemas. Revista Famecos. Porto Alegre, n. 30, agosto, pp. 1630. 2006.

MARTINO, Luiz C.; BERGER, Charles R.; CRAIG, Robert T. Teorias da Comunicação: muitas ou poucas? Cotia, SP: Ateliê Editorial , 2007.

MARTINO, Luiz Claudio. As Epistemologias

Contemporâneas e o Lugar da Comunicação. In: Maria Immacolata Vassalo Lopes (org.) Epistemologia da Comunicação. Loyola. São Paulo, 2003, p. 69-101.

MARTINO, Luiz Claudio. Ceticismo e

Interdisciplinaridade: paradoxos e impasses da teoria da comunicação. Revista Argentina de Comunicación n.3, 2008 .

MARTINO, Luiz Claudio. História e Identidade: apontamentos epistemológicos sobre a fundação e fundamentação do campo comunicacional. Revista eletrônica E-Compós, ed. 1, dez. 2004. Disponível em: www.compos.org.br. Acesso em: 12 nov. 2011.

MORILLO, Fernanda; BORDONS, Maria; GÓMEZ, Isabel. Interdisciplinarity in Science: A Tentative Typology of Disciplines and Research Areas. Journal of the American Society for Information Science and Technology, v. 54, n. 13, p. 1237-1249, 2003.

SANTAELLA, Lucia. Uma cartografia para a inter e transdisciplinaridade. Informática na Educação, v. 8, p. $37-46,2006$.

SHOLLE, David. Resisting Disciplines: Repositioning Media Studies in the University. Communication Theory, n. 5, p. 130-143, 1995. 
STICHWEH, Rudolf. History of Scientific Disciplines.

In: SMELSER, J.; BALTES, Paul B. (editors-in-chief).

International Encyclopedia of the Social \&

Behavioral Sciences, Elsevier, 2001, p. 13727-13731.

TRINDADE, Diamantino F. Interdisciplinaridade: Um

novo olhar sobre as ciências. In: FAZENDA, I. (org.). 0

Que é interdisciplinaridade? São Paulo : Cortez, 2008. 
The Myth of Interdisciplinarity: history and institutionalization of an ideology

El Mito de la Interdisciplinariedad: historia y institucionalización de una ideología

\section{Abstract}

This work presents questions that pursue to better understand the interdisciplinary epistemological point of view. It arises terminological and conceptual aspects) of the terms (interdisciplinarity, transdisciplinarity, multidisciplinarity, indisciplinaridade to critically discuss the project of convergence and unity of knowledge. It discusses the epistemological fragility of interdisciplinary proposal and questions the spread of this movement, characterized as an ideology.

\section{Keywords}

Communication. Interdisciplinarity. Epistemology. Institutionalization of interdisciplinarity. History of interdisciplinarity.

\section{Resumen}

La obra presenta cuestiones que buscan comprender mejor el punto de vista epistemológico interdisciplinario. Hace un breve levantamiento de los aspectos terminológicos (interdisciplinariedad, transdisciplinaridad, multidisciplinariedad, indisciplinaridad) y conceptual del término para analizar críticamente el proyecto de la convergencia y la unidad del conocimiento. Trata sobre la fragilidad epistemológica de la propuesta interdisciplinaria y plantea la cuestión de la difusión de este movimiento, caracterizándolo como una ideología.

\section{Palabras-clave}

Comunicación. Interdisciplinariedad. Epistemología. Institucionalización de la interdisciplinaridad.

Historia de la interdisciplinariedad. 


\section{Expediente}

A revista E-Compós é a publicação científica em formato eletrônico da Associação Nacional dos Programas de Pós-Graduação em Comunicação (Compós). Lançada em 2004, tem como principal finalidade difundir a produção acadêmica de pesquisadores da área de Comunicação, inseridos em instituições do Brasil e do exterior.
E-COMPÓS I www.e-compos.org.br I E-ISSN 1808-2599

Revista da Associação Nacional dos Programas

de Pós-Graduação em Comunicação.

E-compós, Brasilia, v.16, n.1, jan./abr. 2013

A identificação das edições, a partir de 2008,

passa a ser volume anual com três números.

\section{CONSELHO EDITORIAL}

Afonso Albuquerque, Universidade Federal Fluminense, Brasil Alberto Carlos Augusto Klein, Universidade Estadual de Londrina, Brasil Álvaro Larangeira, Universidade Tuiuti do Paraná, Brasil André Luiz Martins Lemos, Universidade Federal da Bahia, Brasil Ângela Freire Prysthon, Universidade Federal de Pernambuco, Brasil Angela Cristina Salgueiro Marques, Faculdade Cásper Líbero (São Paulo), Brasil Antonio Roberto Chiachiri Filho, Faculdade Cásper Líbero, Brasil Arthur Autran Franco de Sá Neto, Universidade Federal de São Carlos, Brasil Benjamim Picado, Universidade Federal Fluminense, Brasil César Geraldo Guimarães, Universidade Federal de Minas Gerais, Brasil Cristiane Freitas Gutfreind, Pontifícia Universidade Católica do Rio Grande do Sul, Brasil

Denilson Lopes, Universidade Federal do Rio de Janeiro, Brasil Eduardo Peñuela Cañizal, Universidade Paulista, Brasil

Eduardo Vicente, Universidade de São Paulo, Brasil Eneus Trindade, Universidade de São Paulo, Brasil Erick Felinto de Oliveira, Universidade do Estado do Rio de Janeiro, Brasil Florence Dravet, Universidade Católica de Brasília, Brasil Gelson Santana, Universidade Anhembi/Morumbi, Brasil Gislene da Silva, Universidade Federal de Santa Catarina, Brasil Guillermo Orozco Gómez, Universidad de Guadalajara Gustavo Daudt Fischer, Universidade do Vale do Rio dos Sinos, Brasil Hector Ospina, Universidad de Manizales, Colômbia Herom Vargas, Universidade Municipal de São Caetano do Sul, Brasil Inês Vitorino, Universidade Federal do Ceará, Brasil Jay David Bolter, Georgia Institute of Technology Jeder Silveira Janotti Junior, Universidade Federal de Pernambuco, Brasil John DH Downing, University of Texas at Austin, Estados Unidos José Afonso da Silva Junior, Universidade Federal de Pernambuco, Brasil José Carlos Rodrigues, Pontifícia Universidade Católica do Rio de Janeiro, Brasil José Luiz Aidar Prado, Pontifícia Universidade Católica de São Paulo, Brasil Kelly Cristina de Souza Prudêncio, Universidade Federal do Paraná, Brasil.
Laan Mendes Barros, Universidade Metodista de São Paulo, Brasil Lance Strate, Fordham University, USA, Estados Unidos Lorraine Leu, University of Bristol, Grã-Bretanha Lucia Leão, Pontifícia Universidade Católica de São Paulo, Brasil Malena Segura Contrera, Universidade Paulista, Brasil

Márcio de Vasconcellos Serelle, Pontifícia Universidade Católica de Minas Gerais, Brasil

Maria Aparecida Baccega, Universidade de São Paulo e Escola Superior de Propaganda e Marketing, Brasil

Maria Ataide Malcher, Universidade Federal do Pará, Brasil

Maria das Graças Pinto Coelho, Universidade Federal do Rio Grande do Norte, Brasil Maria Immacolata Vassallo de Lopes, Universidade de São Paulo, Brasil Maria Luiza Martins de Mendonça, Universidade Federal de Goiás, Brasil Mauro de Souza Ventura, Universidade Estadual Paulista, Brasil Mauro Pereira Porto, Tulane University, Estados Unidos Mirna Feitoza Pereira, Universidade Federal do Amazonas, Brasil Nilda Aparecida Jacks, Universidade Federal do Rio Grande do Sul, Brasil Osvando J. de Morais, Universidade de Sorocaba, Brasil Potiguara Mendes Silveira Jr, Universidade Federal de Juiz de Fora, Brasil Renato Cordeiro Gomes, Pontifícia Universidade Católica do Rio de Janeiro, Brasil Robert K Logan, University of Toronto, Canadá

Ronaldo George Helal, Universidade do Estado do Rio de Janeiro, Brasil Rose Melo Rocha, Escola Superior de Propaganda e Marketing, Brasil Rossana Reguillo, Instituto de Estudos Superiores do Ocidente, Mexico Rousiley Celi Moreira Maia, Universidade Federal de Minas Gerais, Brasil Sebastião Guilherme Albano da Costa, Universidade Federal do Rio Grande do Norte, Brasil

Simone Maria Andrade Pereira de Sá, Universidade Federal Fluminense, Brasil Tiago Quiroga Fausto Neto, Universidade de Brasília, Brasil Suzete Venturelli, Universidade de Brasília, Brasil Valerio Fuenzalida Fernández, Puc-Chile, Chile

Veneza Mayora Ronsini, Universidade Federal de Santa Maria, Brasil Vera Regina Veiga França, Universidade Federal de Minas Gerais, Brasil

\section{COMISSÃO EDITORIAL}

Adriana Braga I Pontifícia Universidade Católica do Rio de Janeiro, Brasil

Felipe Costa Trotta I Universidade Federal Fluminense, Brasil

CONSULTORES AD HOC

Bruno Campanella, Universidade Federal Fluminense, Brasil

Christa Berger, Universidade do Vale do Rio dos Sinos, Brasil

Edison Gastaldo, Universidade Federal Rural do Rio de Janeiro, Brasil

José Luiz Braga, Universidade do Vale do Rio dos Sinos, Brasil

\section{EDIÇÃO DE TEXTO E RESUMOS I Susane Barros}

SECRETÁRIA EXECUTIVA I Juliana Depiné

EDITORACã̃ ELETRÔNICA I Roka Estúdio
COMPóS I www.compos.org.br

Associação Nacional dos Programas de Pós-Graduação em Comunicação

Presidente

Julio Pinto

Pontifícia Universidade Católica de Minas Gerais, Brasil juliopinto@pucminas.br

Vice-presidente

Itania Maria Mota Gomes

Universidade Federal da Bahia, Brasil

itania@ufba.br

Secretária-Geral

Inês Vitorino

Universidade Federal do Ceará, Brasil

inesvic@gmail.com 